\title{
Características de carcaças de suínos alimentados do desmame ao abate em comedouro de acesso único equipado ou não com bebedouro
}

\author{
Carcass characteristics of pigs fed from weaning to slaughter in single space feeder equipped \\ or not with drinker
}

\author{
Paulo Alberto Lovatto ${ }^{1}$ Hernan Vielmo ${ }^{2}$ Vladimir de Oliveira ${ }^{3}$ Luciano Hauschild $^{4}$ \\ Renata Franco Antocheviez ${ }^{5}$ Amanda d'Ávila Carvalho ${ }^{4}$ Marco Antônio Kunrath $^{5}$
}

\section{RESUMO}

\begin{abstract}
Este trabalho avaliou as características de carcaça de suínos alimentados do desmame ao abate em comedouro de acesso único equipado ou não com bebedouro. Foram utilizados 96 animais (48 machos castrados e 48 fêmeas) com peso vivo médio final de $90,5 \mathrm{~kg}$ distribuídos em esquema fatorial $2 \times 2$ (dos tipos de comedouros - acesso único, acesso único equipado com bebedouro; e dois sexos). As carcaças foram avaliadas pelo Método Brasileiro de Classificação de Carcaças e pelo Método de Dissecação. O rendimento de carne magra foi superior em $3,7 \%(P<0,05)$ nos animais alimentados nos comedouros convencionais e 2,6\% inferior $(P<0,05)$ nos machos. A área de olho de lombo não sofreu influência significativa do tipo de comedouro e do sexo. A área de gordura foi cerca de $8,8 \%$ superior $(P<0,05)$ nos animais alimentados nos comedouros conjugados e 16,8\% nos machos. A espessura de toucinho foi $11,0 \%$ superior $(P<0,05)$ nos animais alimentados nos comedouros conjugados e 11,2\% nos machos. A relação carne/gordura foi cerca de $11,0 \%$ superior $(P<0,05)$ nos animais alimentados nos comedouros convencionais e 21,6\% nas fêmeas. O peso do pernil não foi influenciado pelo tipo de comedouro, mas os machos apresentaram um peso de pernil 5,9\% superior $(P<0,05)$ ao das fêmeas. A alimentação de suínos, do desmame ao abate, em comedouro de acesso único conjugado com bebedouro reduz o teor em carne magra e aumenta o teor de gordura na carcaça.
\end{abstract}

Palavras-chave: nutrição, ganho de peso, carne, gordura.

\section{ABSTRACT}

This study was carried out to evaluate the carcass characteristics of pigs fed from weaning to slaughter in single space feeders equipped or not with drinker. Ninety-six animals (48 barrows and 48 females) with $90 \mathrm{~kg}$ live weight were distributed in a factorial design (two feeder types - no drinker; conjugated with drinker; and two sexes). The carcasses were evaluated by the Brazilian Method of Carcasses Classification and by the Dissection Method. The meat yield was 3.7\% higher $(P<0.05)$ in animals fed in dry feeders and $2.6 \%$ slower $(P<0.05)$ in barrows. The carcass yield was not affected by the feeder type, but was $1.3 \%$ higher $(P<0.05)$ in barrows. The loin muscle area was not affected by the feeder type and sex. The fat area was $8.8 \%$ higher $(P<0.05)$ in the animals fed in wet feeders and $16.8 \%$ in barrows. The backfat thickness was $11.0 \%$ higher $(P<0.05)$ in the animals fed in wet feeders and $11.2 \%$ in barrows. The relation meat/fat was $10.9 \%$ higher $(P<0.05)$ in animals fed in dry feeders and $21.6 \%$ in females. The ham weight was not affected by feeder type, but it was $5.9 \%$ higher $(P<0.05)$ in barrows. Feeding pigs from weaning to slaughter in wet feeders reduce lean and increase fat in carcass.

Key words: nutrition, weight gain, meat, fat.

\section{INTRODUÇÃO}

A alimentação de suínos no crescimento e terminação em comedouro/bebedouro conjugados (CBC) melhora a taxa de crescimento e a eficiência alimentar (GONYOU \& LOU, 2000). No entanto, essa melhora estaria relacionada à mudança do comportamento ingestivo dos animais, que gastam menos tempo com o consumo de ração e diminuem os deslocamentos entre o comedouro e bebedouro. A melhor eficiência alimentar estaria, então, relacionada

${ }^{1}$ Departamento de Zootecnia (DZ), Universidade Federal de Santa Maria (UFSM), Campus Camobi, 97105-900, Santa Maria, RS. E - mail: lovatto@smail.ufsm.br. Autor para Correspondência.

${ }^{2}$ Escola Agrotécnica Federal de Dois Vizinhos, Dois Vizinhos, PR, Brasil.

${ }^{3}$ Universidade Estadual do Oeste do Paraná (Unioeste), Mal. Cândido Rondon, PR, Brasil.

${ }^{4}$ DZ, UFSM, Programa de Pós - graduação em Zootecnia, Santa Maria, RS, Brasil.

${ }^{5}$ DZ, UFSM, Santa Maria, RS, Brasil. 
à redução no desperdício de ração e ao menor gasto de energia para atividade física. Como o CBC melhora o ganho de peso, houve um aumento na utilização deste equipamento pelos suinocultores o que instigou o Centro Nacional de Pesquisa de Aves e Suínos a estudos e produção de comunicados técnicos sobre o tema (BELLAVER etal., 1998, BELLAVER \& GARCEZ, 2000). Embora o equipamento continue a ser fabricado, comercializado e utilizado pelos suinocultores, poucos trabalhos realizados no Brasil foram publicados em periódicos indexados. Um desses trabalhos mostra que a alimentação de suínos em comedouros conjugados se revelou interessante no período pré-abate (LOVATTO et al., 2004). No entanto, a ingestão de dietas úmidas altera o consumo e o metabolismo aumentando a espessura de toucinho e a área de olho de lombo (GONYOU \& LOU, 2000). Animais alimentados em comedouros conjugados têm carcaças de qualidade inferior àqueles alimentados em comedouro convencional (MIYAWAKI et al., 1996). Essa redução de qualidade é creditada, à quase sempre, ao aumento da espessura de toucinho e diminuição do rendimento de carne magra. No entanto, existem trabalhos indicando que animais alimentados com dietas úmidas podem ter carcaças de qualidade superior aos animais alimentados com dietas secas (PAYNE, 1991). De maneira geral, a literatura revela uma grande variação nos efeitos do uso de comedouros conjugados sobre as características da carcaça.

A partir dos anos 90, as indústrias brasileiras começaram a remunerar o produtor pela qualidade da carcaça e não mais pelo peso vivo. Isso criou algumas incertezas quanto à recomendação prática do uso de comedouros conjugados, pois, apesar de os animais alimentados nesses equipamentos apresentarem maior taxa de crescimento, suas carcaças apresentavam maior teor de gordura. Os aspectos de desempenho foram estudados por LOVATTO et al. ( 2004), que verificaram superioridade do CBC, mas não identificaram os cortes ou tecidos (muscular ou adiposo) beneficiados por esse crescimento diferencial. Portanto, este trabalho foi realizado com o objetivo de estudar as características da carcaça de suínos alimentados do desmame ao abate em comedouro de acesso único equipado ou não com bebedouro.

\section{MATERIAL E MÉTODOS}

O trabalho pré-abate foi realizado no Setor de Suinocultura do Departamento de Zootecnia da Universidade Federal de Santa Maria, RS, Brasil, nos meses de primavera e verão. Foram utilizados 96 animais (48 machos castrados e 48 fêmeas) F1 (Large White x
Landrace) x Duroc oriundos de criação comercial, com idade média de 21 dias e peso médio inicial de $6,27 \mathrm{~kg}$. As fases de creche, crescimento e terminação foram de 42 dias cada. Instalações: creche - 24 baias (1,30 x 1,37 x $0,70 \mathrm{~m}$ ) elevadas a $0,60 \mathrm{~m}$ do piso, metade de plástico vazado. Crescimento e terminação - 24 baias de 3,20 x $1,40 \times 0,90 \mathrm{~m}$. Equipamentos: creche - comedouro conjugado de acesso único com $25 \mathrm{~cm}$ lineares, depósito para $8 \mathrm{~kg}$ de ração seca e bebedouro tipo chupeta instalado dentro do alimentador; comedouro convencional (mesmas características do conjugado, exceto a saída de água que foi vedada). O equipamento foi adquirido no mercado brasileiro (marca SUIN), sendo construído em fibra de vidro, exceto o sistema semi-automático de descida de ração e a proteção da borda superior do alimentador, que eram de aço inoxidável. Crescimento e terminação - comedouro conjugado de acesso único com $35 \mathrm{~cm}$ lineares, depósito para $40 \mathrm{~kg}$ de ração e bebedouro do tipo chupeta instalado dentro do alimentador; comedouro convencional (mesmas características do conjugado exceto o bebedouro, sendo do tipo chupeta localizado na porção posterior da baia). O equipamento foi construído em alvenaria, exceto o sistema semiautomático de descida de ração que era metálico. Os animais foram abatidos com peso vivo médio de 90,5 quilogramas.

Os estudos pós-abate foram realizados no Frigorífico Chapecó S.A. (Santa Rosa, RS). Após a chegada ao frigorífico, os animais foram pesados e alojados em baias específicas para completar o jejum pré-abate de sólidos por um período médio de 24 horas. $\mathrm{O}$ abate seguiu as normas do Serviço de Inspeção Federal com insensibilização elétrica, sangria, depilação, evisceração, inspeção e resfriamento. Após 24h armazenadas em câmaras de resfriamento, as carcaças foram transferidas para a sala de avaliação. Os dados de carcaça foram obtidos através de dois métodos: (1) Método Brasileiro de Classificação de Carcaças MBCC, (ABCS, 1973) e, (2) Método de Dissecação MD (IRGANG \& PROTAS, 1986). Todas as carcaças foram avaliadas pelo MBCC e 24 pelo método de dissecação. Para o MD foi selecionado o segundo animal mais pesado de cada uma das 24 unidades experimentais, totalizando 6 animais por tratamento (GUIDONI, 1994). As variáveis analisadas foram: pelo MBCC - peso de abate, peso de carcaça quente, peso de carcaça fria, rendimento de carcaça, comprimento de carcaça, área de olho de lombo, área de gordura, espessura de toucinho, relação carne/gordura e peso do pernil. O MD prevê a análise de 51 variáveis da carcaça, sendo que algumas delas são igualmente levadas em conta pelo MBCC. Por essa razão, foram

Ciência Rural, v.36, n.1, jan-fev, 2006. 
utilizadas as variáveis do MD de maior interesse analítico que diferem do MBCC: rendimento de pernil, carne magra, gordura e pele, ossos, costela, papada, pescoço, cabeça, cauda e ponta de lombo e resíduo. $\mathrm{O}$ MD não prevê a análise de peso de carcaça quente.

O delineamento utilizado foi um fatorial $2 \times 2$ (dois tipos de comedouros; dois sexos: T1 - machos COC; T2 - machos CBC; T3 - fêmeas COC; T4 - fêmeas $\mathrm{CBC})$, com seis repetições de quatro animais cada. A unidade experimental foi constituída de um animal. Os dados foram submetidos à análise de variância, incluindo no modelo os efeitos do tipo de comedouro (TC) e sexo (S) através do MINITAB (MCKENZIE \& GOLDMAN, 1999). As médias que diferiram estatisticamente foram comparadas pelo teste T. A interação TC e S foi estudada, mas, por não ter influenciado significativamente as respostas, foi excluída do modelo. Para todas as variáveis analisadas, foi utilizado o peso inicial como covariável.

\section{RESULTADOS E DISCUSSÃO}

Os resultados obtidos através do MBCC são apresentados na tabela 1 . As variáveis da carcaça que diferiram significativamente $(\mathrm{P}<0,05)$ para os animais alimentados nos comedouros convencionais foram o peso de abate $(3,8 \%$ inferior), peso de carcaça fria $(4,5 \%$ inferior), comprimento de carcaça (1,3\% inferior), área de gordura $(9,7 \%$ inferior), espessura de toucinho (12,2\% inferior) e relação carne/gordura (9,9\% superior). As variáveis da carcaça não influenciadas $(\mathrm{P}>0,05)$ pelo tipo de comedouro foram o rendimento de carcaça, a área de olho de lombo e o peso do pernil.

Com relação ao sexo, os resultados foram significativamente diferentes $(\mathrm{P}<0,05)$ para os machos nas variáveis de peso de abate $(6,0 \%$ superior $)$, peso de carcaça (7,2\% superior), rendimento de carcaça fria (1,3\% superior), área de gordura ( $16,8 \%$ superior), espessura de toucinho (11,2\% superior), relação carne/ gordura (21,6\% inferior) e peso de pernil (5,9\% superior).

$\mathrm{O}$ uso de comedouros conjugados com bebedouros do desmame ao abate aumenta o ganho de peso (LOVATTO et al., 2004). No entanto, os dados observados, no presente estudo, mostram que parte desse ganho se deve ao acúmulo de gordura. Isso confirma, em parte, que o programa alimentar permitiu a expressão do potencial genético sendo o excesso de nutrientes (provavelmente esqueletos de carbono oriundos da desaminação) utilizados para a lipogênese (KAREGE, 1991). Os resultados de diferenciação entre sexos com um aumento da espessura de toucinho dos machos em relação às fêmeas confirmam observações anteriores (BIKKER et al., 1994, BELLAVER et al., 1998, FABIAN et al., 2003).

Os valores das principais variáveis avaliadas pelo Método de Dissecação são apresentadas nas tabelas 2 e 3 . Dentre os principais resultados, destacamse o rendimento de carne magra, 3,7\% superior $(\mathrm{P}<0,05)$ nos animais alimentados nos comedouros convencionais e $2,6 \%$ superior $(\mathrm{P}<0,05)$ nas fêmeas. Esses resultados se contrapõem àqueles do Método Brasileiro, revelando a importância do método utilizado para quantificar o rendimento de carcaça.

As variáveis da carcaça significativamente melhores $(\mathrm{P}<0,05)$ expressas em valores relativos para os animais alimentados nos comedouros convencionais foram: gordura e pele (13,3\% inferior), barriga (5,2\% inferior), carré ( $0,8 \%$ superior) copa ( $4,2 \%$ superior), pernil (4,1\% superior) e a carne de origem no carré (10,5\% superior). As variáveis da carcaça expressas em valores relativos não influenciados $(\mathrm{P}>0,05)$ pelo tipo de comedouro foram a massa óssea, papada,

Tabela 1 - Peso de abate (PBT, kg), peso de carcaça fria (PCF, kg), rendimento de carcaça (REC, \%), comprimento de carcaça (CPC, cm), área de olho de lombo (AOL, $\mathrm{cm}^{2}$ ), área de gordura $\left(\mathrm{AGO}, \mathrm{cm}^{2}\right)$, espessura de toucinho (ETO, $\left.\mathrm{cm}\right)$, relação carne/gordura (RCG) e peso do pernil (PPR, kg) de suínos alimentados, do desmame ao abate em comedouros de acesso único equipado (CBC) ou não com bebedouro (COC) obtidos pelo Método Brasileiro de Classificação de Carcaças.

\begin{tabular}{llllllllll}
\hline Variável & PBT & PCF & REC & CPC & AOL & AGO & ETO & RCG & PPR \\
\hline COC & 88,85 & 71,56 & 80,52 & 94,29 & 35,75 & 21,28 & 2,54 & 1,72 \\
CBC & 92,25 & 74,81 & 81,07 & 95,53 & 34,94 & 23,34 & 2,85 & 1,55 \\
Machos & 93,35 & 75,9 & 81,32 & 95,33 & 35,00 & 24,36 & 2,85 & 1,48 & 11,68 \\
Fêmeas & 87,75 & 70,47 & 80,27 & 94,50 & 36,69 & 20,26 & 2,53 & 1,80 & 10,99 \\
\hline dpr & 3,95 & 3,30 & 0,62 & 1,38 & 1,66 & 1,79 & 0,23 & 0,15 & 0,55 \\
\hline Efeito, P<0,05 & $\mathrm{C}, \mathrm{S}$ & $\mathrm{C}, \mathrm{S}$ & $\mathrm{S}$ & $\mathrm{C}$ & $\mathrm{NS}$ & $\mathrm{C}, \mathrm{S}$ & $\mathrm{C}, \mathrm{S}$ & $\mathrm{C}, \mathrm{S}$ & $\mathrm{S}$ \\
\hline
\end{tabular}

dpr, desvio padrão residual; NS, não significativo; significativo para C, comedouro; S, Sexo 
Tabela 2 - Carne magra (CAR, \%), gordura e pele (GOP, \%), ossos (OSS, \%), costela (COS, \%), papada (PAP, \%), pescoço (PES, \%), cabeça (CAB, \%), cauda e ponta de lombo (CPLO, \%), resíduo (RES, \%) e pernil (PER, \%) de suínos alimentados, do desmame ao abate em comedouros de acesso único equipado (CBC) ou não com bebedouro (COC) obtidos pelo Método de Dissecação.

\begin{tabular}{|c|c|c|c|c|c|c|c|c|c|c|}
\hline Variável & CAR & GOP & OSS & $\mathrm{COS}$ & PAP & PES & $\mathrm{CAB}$ & CPLO & RES & PER \\
\hline $\mathrm{COC}$ & 54,91 & 24,89 & 9,28 & 1,44 & 0,97 & 2,01 & 5,44 & 0,56 & 0,50 & 31,14 \\
\hline $\mathrm{CBC}$ & 52,89 & 28,20 & 8,42 & 1,42 & 1,05 & 1,95 & 5,19 & 0,48 & 0,44 & 30,88 \\
\hline Machos & 53,20 & 27,27 & 8,69 & 1,34 & 1,02 & 1,95 & 5,57 & 0,48 & 0,48 & 30,09 \\
\hline Fêmeas & 54,60 & 25,82 & 9,22 & 1,52 & 0,97 & 2,01 & 5,06 & 0,56 & 0,46 & 30,88 \\
\hline dpr & 3,95 & 3,30 & 0,62 & 1,38 & 1,66 & 1,79 & 0,23 & 0,15 & 0,55 & 0,67 \\
\hline Efeito, $\mathrm{P}<0,05$ & $\mathrm{C}, \mathrm{S}$ & $\mathrm{C}, \mathrm{S}$ & $\mathrm{S}$ & $\mathrm{C}$ & NS & $\mathrm{C}, \mathrm{S}$ & $\mathrm{C}, \mathrm{S}$ & $\mathrm{C}, \mathrm{S}$ & $\mathrm{S}$ & NS \\
\hline
\end{tabular}

dpr, desvio padrão residual; NS, não significativo; significativo para C, comedouro; S, Sexo;

resíduos, pernil, paleta, cabeça e papada e carne de origem na paleta. As variáveis da carcaça expressas em valores relativos significativamente piores $(\mathrm{P}<0,05)$ para os animais alimentados nos comedouros convencionais foram a massa de costela ( $1,4 \%$ superior), pescoço ( $3,1 \%$ superior), cabeça ( $4,6 \%$ superior), cauda e ponta de lombo (14,3\% superior), resíduos, pés e cauda $(6,8 \%$ superior).

Com relação ao sexo, os resultados foram significativamente diferentes $(\mathrm{P}<0,05)$ para os machos nas variáveis de gordura (5,3\% superior), massa óssea (6,1\% inferior), pescoço ( $3 \%$ superior), cabeça $(9,2 \%$ superior), cauda e ponta de lombo ( $16,7 \%$ inferior), resíduos (4,2\% superior), barriga ( $1,8 \%$ inferior), carré (3,7\% inferior), paleta ( $4,3 \%$ superior), resíduos, pés e cauda (3,4\% inferior), carne de origem de pernil $(3,4 \%$ inferior), carne de origem da copa (5,8\% superior), carne de origem na paleta ( $1,9 \%$ inferior).

Os comedouros conjugados permitem a ingestão de alimentação úmida pelos animais, mas os resultados apresentados na literatura são divergentes quanto a qualidade de carcaça. A alimentação úmida pode melhorar as características da carcaça e da carne. Isso se daria pela redução da energia necessária para atividade física, sobretudo nos deslocamentos entre comedouro e bebedouro e disputa pelo espaço no comedouro (GONYOU \& LOU, 2000). Dessa forma, o aporte energético das dietas poderia ser reduzido em função da pouca atividade física e/ou a energia economizada seria destinada à síntese protéica. Mas, em muitos casos, a alimentação úmida proporcionada pelos comedouros conjugados, mantém as características da carcaça e da carne inalteradas (MATON \& DAELEMANS, 1991, MIYAWAKI et al., 1996). Em outras situações, como neste experimento, os comedouros conjugados podem diminuir as características desejáveis da carcaça e da carne (WALKER, 1990, BELLAVER et al., 1998). Nesse caso, é provável que os animais tenham uma ingestão elevada, o que determinaria uma disponibilidade de nutrientes acima do potencial máximo de deposição protéica - PD $_{\max }$ (EMMANS \& KYRIAZAKIS, 1997).

Dessa forma, haveria uma desaminação de aminoácidos sendo a cadeia de carbonos usada para a lipogênese, aumentando a massa de gordura da carcaça.

Tabela 3 - Barriga (BARI, \%), carré (CARR, \%), paleta (PALE, \%), copa (COP, \%), cabeça e papada (CAPA, \%), resíduos, pés e cauda (RPCA, \%), carne de origem no pernil (CPER, \%), carne de origem na copa (COPA), carne de origem na paleta (CPLE), carne de origem no carré (CCAR) de suínos alimentados, do desmame ao abate em comedouros de acesso único equipado (CBC) ou não com bebedouro (COC) obtidos pelo Método de Dissecação.

\begin{tabular}{|c|c|c|c|c|c|c|c|c|c|c|}
\hline Variável & BARI & CARR & PALE & $\mathrm{COP}$ & CAPA & RPCA & CPER & COPA & CPLE & CCAR \\
\hline $\mathrm{COC}$ & 17,34 & 15,61 & 19,02 & 7,86 & 6,41 & 3,07 & 18,73 & 3,97 & 9,61 & 6,25 \\
\hline $\mathrm{CBC}$ & 18,25 & 15,49 & 19,34 & 7,53 & 6,21 & 2,86 & 17,97 & 3,73 & 9,36 & 5,59 \\
\hline Machos & 17,64 & 15,24 & 19,62 & 7,86 & 6,58 & 2,92 & 18,04 & 3,97 & 9,39 & 5,69 \\
\hline Fêmeas & 17,96 & 15,80 & 18,78 & 7,53 & 6,03 & 3,02 & 18,66 & 3,74 & 9,57 & 6,15 \\
\hline $\mathrm{dpr}$ & 3,95 & 3,30 & 0,62 & 1,38 & 1,66 & 1,79 & 0,23 & 0,15 & 0,55 & 0,62 \\
\hline Efeito, $\mathrm{P}<0,05$ & $\mathrm{C}, \mathrm{S}$ & $\mathrm{C}, \mathrm{S}$ & $\mathrm{S}$ & $\mathrm{C}$ & $\mathrm{NS}$ & $\mathrm{C}, \mathrm{S}$ & $\mathrm{C}, \mathrm{S}$ & $\mathrm{C}, \mathrm{S}$ & $\mathrm{S}$ & $\mathrm{C}$ \\
\hline
\end{tabular}

dpr, desvio padrão residual; NS, não significativo; significativo para C, comedouro; S, Sexo;

Ciência Rural, v.36, n.1, jan-fev, 2006. 


\section{CONCLUSÃO}

A alimentação de suínos, do desmame ao abate, em comedouro de acesso único conjugado com bebedouro reduz o teor em carne magra e aumenta o teor de gordura na carcaça.

\section{AGRADECIMENTOS}

Ao Conselho Nacional de Desenvolvimento Científico e Tecnológico (CNPq), pela concessão de bolsa de Iniciação Científica ao pesquisador Hauschild.

Ào Fundo Institucional de Extensão (FIEX/UFSM), pela concessão de bolsa ao pesquisador Antocheviez.

À Fundação de Apoio à Pesquisa do Estado do Rio Grande do Sul (FAPERGS), pela concessão de bolsa ao pesquisador Kunrath.

\section{REFERÊNCIAS}

ABCS. Método brasileiro de classificação de carcaças. Estrela: Associação Brasileira de Criadores de Suínos, 1973. p.14.

BELLAVER, C.; GARCEZ, D.C.P. Comedouros para suínos em crescimento e terminação. Concórdia: Embrapa-CNPSA, 2000 .

BELLAVER, C. et al. Fornecimento de água dentro do comedouro e efeitos no desempenho, carcaça e efluentes da produção de suínos. Concórdia: Embrapa-CNPSA, 6p. 1998.

BIKKER, P. et al. Digestible lysine requirement of gilts with high genetic potential for lean gain, in relation to the level of energy intake. Journal Animal Science, v.72, p.1744-1753, 1994.

EMMANS, G.C.; KYRIAZAKIS, I. Models of pig growth problems and proposed solutions. Livestock Production Science, v.51, p.119-129, 1997.

FABIAN, J. et al. Growth performance, dry matter and nitrogen digestibilities, serum profile, and carcass and meat quality of pigs with distinct genotypes. Journal Animal Science, v.81, p.1142-1149, 2003

GONYOU, H.W.; LOU, Z. Effects of eating space and availability of water in feeders on productivity and eating behavior of grower/finisher pigs. Journal Animal Science, v.78, p.865-870, 2000.

GUIDONI, A.L. Alternativas para comparar tratamentos envolvendo o desempenho nutricional animal. 1994. Tese (Doutorado) - Universidade de São Paulo, Piracicaba.

IRGANG, R.; PROTAS, J.F.S. Peso ótimo para abate de suínos. Pesquisa Agropecuária Brasileira, v.21, p.1337-1345, 1986.

KAREGE, C. Influence de l'age et du sexe sur l'utilisation de l'énergie et la composition corporelle chez le porc en croissance. 1991, 254f. Thesis (Doctor) - Université Montpellier II, Montpellier.

LOVATTO, P. A. et al. Desempenho de suínos alimentados do desmame ao abate em comedouro de acesso único equipado ou não com bebedouro. Ciência Rural, v.34, p.200-210, 2004.

MATON, A.; DAELEMANS, J. Study of the wet-feed hopper versus the dry-feed hopper for finishing pigs. Revue de l'Agriculture, v.44, p.35-39, 1991.

MCKENZIE, J.; GOLDMAN, R.N. The student edition of Minitab for Windows Manual: Release 12. Belmont: Addison-Wesley Longman, 1999. 592p.Incorporated: Softcover ed

MIYAWAKI, K. et al. Effects of wet/dry feeding for finishing pigs on growth, feed conversion and carcass quality. Japan Journal Swine Science, v.33, p.5-13, 1996.

PAYNE, H.G. The evaluation of single-space and wet-and-dry feeders for Australian environment. In: BIENNAL CONFERENCE OF THE AUSTRALASIAN PIG SCIENCE ASSOCIATION, 3., 1991. p.158-161.

WALKER, N. The influence of hopper-type feeders on performance of pigs. Pig News and Information, v.11, p.3133, 1990. 